\title{
Investigation Of The Relationship Between Plasma Tryptophan Metabolite Levels And Lithium Treatment Response In Euthymic Bipolar Patients
}

\author{
Okan İmre $^{1}$, Kürsat Altninbas ${ }^{2}$, Sedat Abuşoğlu ${ }^{3}$, Ali Unlu ${ }^{3}$, and Mehmet İyisoy ${ }^{4}$ \\ ${ }^{1}$ Karamanoglu Mehmetbey University \\ ${ }^{2}$ Selçuk University Faculty of Medicine \\ ${ }^{3}$ Selcuk Universitesi Tip Fakultesi \\ ${ }^{4}$ Necmettin Erbakan Üniversitesi Meram Tip Fakültesi
}

July 21, 2021

\begin{abstract}
Objective: Lithium is a cornerstone treatment option in bipolar disorder. Currently, only clinical findings are used to predict the response of lithium treatment but reliable biological marker has not yet been identified. With this background, it was aimed to compare tryptophan metabolite levels between bipolar patients and healthy control group and to investigate the relationship between lithium treatment response and tryptophan metabolite levels of euthymic bipolar patients(BP). Materials and Methods: 52 euthymic BP patients on lithium were included in the study. Sociodemographic and clinical information were recorded and lithium treatment response status was determined according to the Alda scale. Age and gender matched Healthy controls(HC) were selected from the people who admitted to Selcuk University Medical Faculty Hospital Health Board. Plasma tryptophan metabolite levels were compared between BP and HC. The correlation and association between the lithium response levels of the patients and the plasma tryptophan metabolites were evaluated. Results: Plasma tryptophan(TRP), kynurenine(KYN), kynurenine/tryptophan ratio(KYN/TRP), 3-hydroxy-kynurenine(3-HK) and kynurenic acid(KYNA) levels were significantly lower in $\mathrm{BP}$ than $\mathrm{HC}$. In the regression analysis, only plasma KYNA concentrations were found to be significantly lower in the responding well to lithium treatment and TRP levels. None of the tryptophan metabolites were found to be associated well response to lithium treatment after the logistic regression analysis. Conclusion: Our findings indicate that KYNA levels might be used as a screening test for discriminating bipolar patients from the HC. TRP levels might be used to predict lithium treatment response in spite of low specifity and low sensitivity levels. Key words: Tryptophan metabolites, lithium treatment response, bipolar disorder
\end{abstract}

\section{Hosted file}

Main Document.docx available at https://authorea.com/users/426763/articles/531163investigation-of-the-relationship-between-plasma-tryptophan-metabolite-levels-andlithium-treatment-response-in-euthymic-bipolar-patients

\section{Hosted file}

Tables.docx available at https://authorea.com/users/426763/articles/531163-investigationof-the-relationship-between-plasma-tryptophan-metabolite-levels-and-lithium-treatmentresponse-in-euthymic-bipolar-patients 